\title{
الشيخخ ناصر الدين الألباني ومكانته العلمية في مجال علم الحديث
}

\section{Al Sheikh Nasir ud din Albani and his statues in the field of Hadith}

شابنواز"

الدكتوررنعيم انور الازهرى

\section{ABSTRACT:}

Islam is the Deen that fits to the man's nature. Allah Almighty sent his various messengers to convey His Commandments to the mankind. For His final Commandments, Allah Almighty sent Prophet Muhammad (SWA).He also introduced His personalityas a explanatory status in Quran, This act has been mentioned on several occasion in Holy Quran which is fully agreed by the whole Umaah. For this, Holy Quran and hadith share the same importance for the guidance of Muslims. The companions of Rasool (SAW), Tabi' in, Tabi al- Tabi'in and Muhdseen tried their level best to collect and do rearrangement of the Hadith., according to their potentialMohedseen compiled the collection of Hadith at different places during different time periods. This collection of Hadith is known as Sihah, Sitta in Islamic history. With the passage of time, there are so many controversial personalities who tried to damage the importance of this Islamic castle. Moreover, there came some personalities who didn't have the command on Hadith and its sciences. They even brought their own changes in this regard. Among such names, Al- Sheikh Nasir ur Din Albani is the one, who challenged the authenticity of SihahSitta and other books of Hadith such as Al- AdabulMufrid and Al TarghebwaTerhaib etc. But Allah Almighty always sent such people who defended the matters related to the authenticity of Haidth. In this very article, Sheikh Al bani, his knowledge, his research and his challenges related to the authenticity of Haidth will be analyzed.

Key Words: Hadith and its sciences ,Sayings of Muhdseen, states of sheikh Al Bani, Status of Sheikh Al-Bani in Hadith, Suhufi.

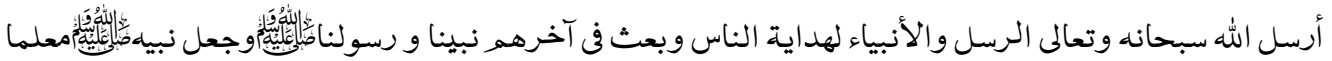

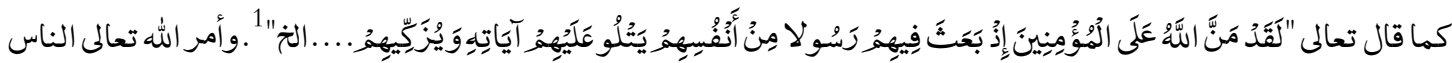

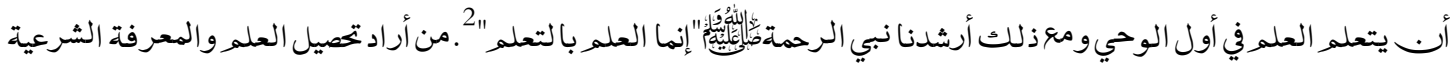

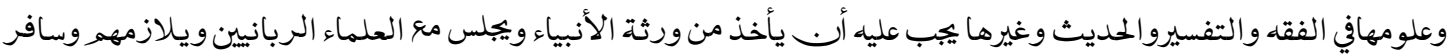

$$
\begin{aligned}
& \text { إلى من هو أهله كما ورد في صحيح البخاري أب الرحلة لطلب الحديث هي سنة الصحابة وبوب الإمام البخاري في صحيحه بابا }
\end{aligned}
$$

"PhD Scholar, GCU Lahore / Lecture, Cadet College ChoakSaidian Shah, Chakwal. Email: shahnawaz.ih@gmail.com Assistant Professor, Department of Arbic \& Islamic Studies, GC University, Lahore. 
وسماه"باب الخرو جفي طلب العلم_ وذكرفيه رحلة "جابربن عبد الله"مسيرته شهر إلى عبد الله بن أنيس في حديث واحد"3 هذا من سنة الصحابة رضوات. الله عليهم أجمعين وعليه عمل أهل العلمر ممن بعدهم حتى إلى عصرنا تواترا، ومعذذلك حذر أهل العلمر من أرــ يؤخذ عن كل أحد كما قال عبد الله بن مبارك"إِ. هذا العلمر دين فانظروا عمن تأخذوب. دينكم، "4هذه الأحاديث وأمثاله يقرروجوب أخذالعله من العلماء وملازمتهم و التلقي عنهم وليس من الكتب والأوراق لأَّـ النبي صلى الله عليه وآله وسلمأشار إليه أبــ ذهاب العلم هو ذهاب حملته لم يقل أبـ ذهاب العلمه هو ضياء الكتب ويدل الحديث أُــ مصادر العلومرهو صدور العلماء، ولذا أمر رسول الله صلى الله عليه وآله وسلمأر. يأخذ العلمـ ممن هو أهله لا من الصحف والأوراقوالكتب.

\section{ترجمة موجزة للشيخ الألباني وأقوال أهل العلمفيه:}

هو الشيخ العلامة أبوعبد الرحمن محمدناصر الدين بن نوحنجاتي بن آدم الألباني" .5 كانت ولادته عام 1332ه الموافق 1914مرفي مدينة أشقودرة عاصمة ألبانية في ذلك الوقت.نشألشيخ الألباني فى أسرة فقيرة ,متدينة يغلب عليها الطابع العلمي فقد تخرج والده الحاج نوح الحنفي رحمه الله في المعاهد الشرعية في العاصمة العثمانية فورجع إلى بلاده لخدمة الدين وتعليمر الناس ما درسه . كار. الشيخ الألباني بعد هجرة والده من ألبانية إلي الشامقد شارف على التاسعة من عمرهوأدخله والده في مدرسة "جمعية الإسعاف الخيري"وأتم فيها المرحلة الإبتدائية لكن لم يكمل دراسته في مدرسة النظامية ووضع له والده برنامجا خاصا ،حفظ الشيخ الألباني القرآتـ على يد والده على رواية "حفص"ودرَّس بعض كتب الصرف والنحو ومختصر القدوري في الفقه الحنفيثم درّسه مراقى الفلاح وشذور الذهب في النحو وكما أنه حضر دروس العلامة محمد بهجت البيطار وكا. ــ الشيخ الألباني من أول حياته مغرما بالمطالعة و القراءة.أخذ عن يد أبيه مهنة اصلاحات الساعات فأجادها حتى صار من أصحاب الشهرة فيها وأخذ يكسب رزقه منها ـ اتفق كل من ترجم للشيخ الألباني على أت. عدد شيوخه لمـ يبلغ إلا أربعة بل ذكر بعضهم ثلاثة. وهؤلاء ....نوح نجاتي بن آدم الألباني، الشيخ محمد سعيد البرهاني، محمد بهجت البيطار، الشيخ محمد راغب الطباخ .8قال الشيخ إبراهيم الشيباني: تتلمذ على يد الشيخ الألباني كثير من الناس ، فمنهم من تلمذ على يديه مباشرة، وهم قليل ،ومنهـ تلمذ به من غير مباشرة أي تلمذ على كتبه ومحاضراتموهم كثيرور ــنا نذكر بعض أسماء من تتلمذوا على يديه مباشرة."الشيخ حمدي عبد المجيد السلفي، الشيخ عبد الرحمن عبد الخالق السلفي، الشيخ مقبل بن هادي الوداعيا لشيخ عبد الرحمن الألباني (ابنه) حمد بن إبراهيم الشيباني". كابـــوفاة الشيخ الألباني في يوم السبت الثاني والعشرين من جمادى الأخرة لعام عشرين وأربع مائة وألف من الهجرة

النبوية الموافتق 1999مربعد العصر. 10

ثناء العلماء عليه من أهل السلفية وأقوالهمر:

قال الشيخ عبد العزيز بن عبد الله بن باز :"الشيخ الألباني معروف أنه من أهل السنة والجماعة ومن أنصار السنة ومن دعاة السنة ومن الهجاهدين في سبيل حفظ السنة.وأيضا يقول :"لا أعلدتحت قبة الفلك في هذا العصر أعلم من الشيخ ناصر الألباني

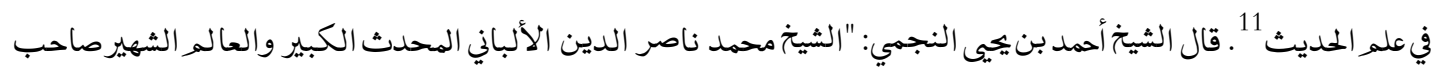


التأليف النافعة والتخريجات المفيدة ,سوري الموطن سلفي العقيدة بذل جهدا في التخريج لا يوازيه فيه أحد فجزا الله خيرا. 12

\section{أقوال بعض أمل العلف من أمل السنة:}

قال الشيخ الطنطاوي: "الشيخ ناصر أعلم مني في علوم الحديث وأنا أحترمه لجده ونشاطه وكثرة تصانيفه التي يطبحها له

أخي وولدي النابغة زهير الشاو يش وأنا أرجء إلى الشيخ ناصر في مسائل الحديث ولا أستنكف أُ. أساله عنها معترفا بفضله وأنكر عليه إذا تفقه فخا لف ما عليه الجمهور لأنه ليس بفقيه"13 ويقول أيضا"إذا كارِ للشيخ ناصر عذرا إذا اجتهد فأخطافماعذرمن يقلده و يترك جماعة الفقهاء والأئمة المحققين من المحدثين أليس خيرا له لو مشى مع القافلة على الجادة الواضحة ولمر يسلك الطريق الذي انفرد بسلوكهو واحد.؟ثم قال "الدين النصحيحة ,أنا ارجو من أخي الشيخ ناصر ألا يغرق جماعة المسلمين باجتهادات فردية

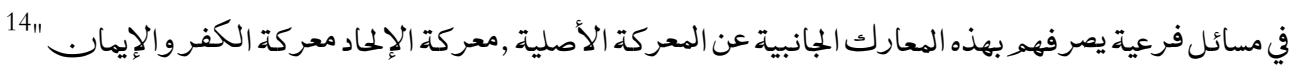
قال الشيخ الحافظ أبو الفضل عبد الله بن الصديق الغماري 15 من قرأكتاب سعيد ممدوح "تنبيه المسلمـ إلى تعدي الألباني على صحيح مسلم "تبين له أبـ الألباني ضعيف في علم الحديث متنا ورجالا ، بخلاف ما يدعيه لنفسه" "16.وقال أيضا فإنه أي الشيخ الألباني كثير الدعوى ،سفيه اللساب شتام هجام فيه زعارة 17 وعرامة قبيحة ، كأنه لمر يقرأ الأحاديث الذامة لسوء الخلق والناهية عن السب والشتم. 19

ألف الشيخ الألباني كتبا كثيرة وأيضا حققها كتب الأئمة على حسب تأييد مذهبه وخرج أحاديثها واعتمد في تخقيقاته وتخريجاته على مخطوطات المكتبة الظاهرية، ومن تصنيفاته:"سلسلة الأحاديث الصحيحة" والضعيفة، "صحيح وضعيف الترغيب والترهيب "صحيح وضعيف الأدب المفرد"صحيح وضعيف الجامع الصغير "صحيح وضعيف سنن ابن ماجة صحيح وضعيف سنن أبي

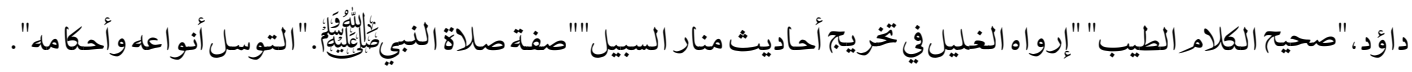
تعريف الصحفي والمصحفي عند علماء اللغة وعلماء الأصول: تعريف الصحفي لغة: قال ابن منظور:صحف الصحيفة التي يكتب فيها والجمهاء صَحائفُ وصُحُفُّكماجاء في التنزيل "صحُفِف إبراهيمووموسى"

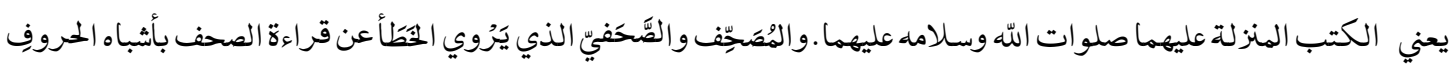

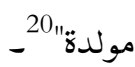

\section{تعريف الصحفي اصطلاحا:}

قال صاحب المعجم الوسيط"الصحفي من يأخذالعلم من الصحيفة لاعن أستاذ ومن يزاول حرفة الصحافة" (محدثة) .21.

المصحفي الذي يقرأ من المصحف مباشرة،ويقال:"لا تأخذوا العلمـ من صحفي"أي من يقرأ في الكتب دور. التتلمذ"22.ويقول أهل العله "لا تأخذوا العله من صحفي ولا مصحفي، يعن: لا يقرأ القرآــ على من قرأ من المصحف، ولا الحديث وغيره على من أخذذلك من الصحف.

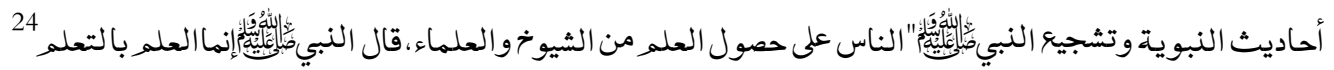




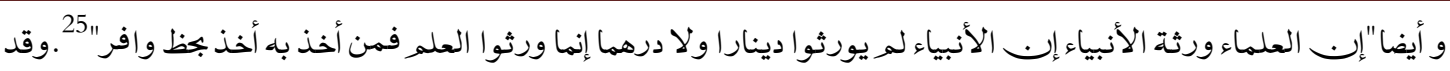
جاءفى حديث آخر:"إِـ الله لا يقبض العلمر انتزاعا ينتزعه من الناس ولكن يقبضه بقبض العلماء" ل26.فيه أمور الأمر الأول من أراد تخصيل العلم ييب عليه أربـ يأخذ من ورثة الأنبياء كما شجع النبي صلي الله عليه وآله وسلم، ويجلس في مجالس العلماء الربانيين ويلازمهم وسافر إلى من هو أهله كما ورد في صحيح البخاري أب. الرحلة لطلب الحديث هي سنة الصحابة. والأمر الثاني:وهو مهم جدا وهو محرفة من يؤخذ عنه علوم الدين وأصوله فلا يؤخذ من كل واحد ،كما أشار إليه

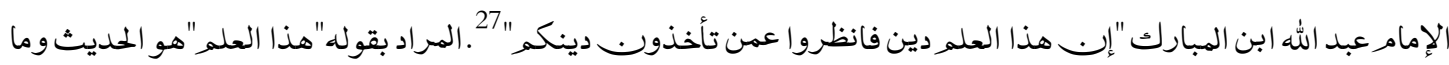

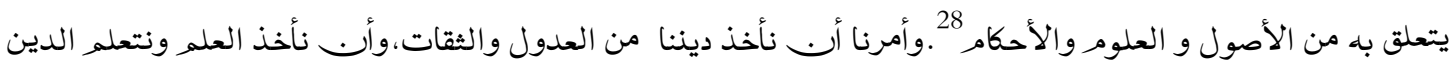
وأصوله ممن هو أهله وعليه عمل أهل العله من الصحابة والتابعين والفقهاء والمحدثين والأصوليين منذ عهد النبي صلى الهه عليه وآله وسلمحتى عصرنا هذا. و الأمر الثالث:وجوب أخذ العلم من المعلم والعلماء الربانيين وقدحث النبي صلى الله عليه وآله وسلمر عليه أصحابه

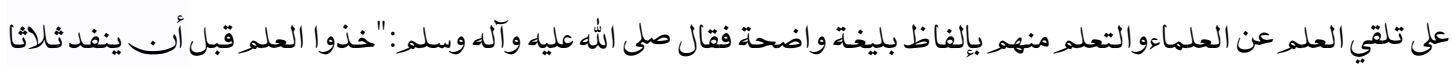
قالوا : يا رسول الله وكيف ينفذوفينا كتاب الله؟ فغضب لا يخضبه الله ثرق قال :ثكلتكم أمهاتكم ألر تكن التوارة والإنجيلفي بني

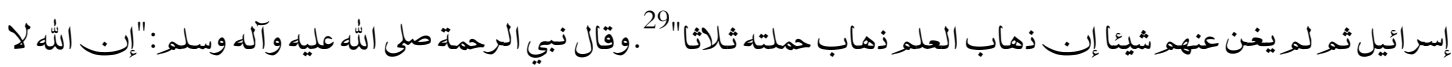
يقبض العلمر انتزاعا ينتزعه من الناس ولكن يقبضه بقبض العلماء"30. .وترجمر الإمام البخاري في كتاب العلم باب بقوله صلى

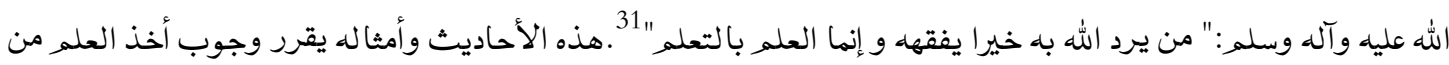
العلماءوملازمتهم و التلقي عنهم وليس من الكتب والأوراق. إبـ التعلم بالكتب والصحف والأوراق فقط دوبـ ورثة الأنبياء يعتبروه علماء الملة الإسلامية أعظم بلية،

ويقولوبـ :تشيخ الصحيفة، أى تعلم من الصحف كما قاله ابن جماعة الكناني 32 أخرج الخطيب البغدادي في"الفقيه والهتفقه" بسنده عن سليماب بـ بن أبي شيخ قال : أخبرني بعض الكوفيين قال : قيل لأبي

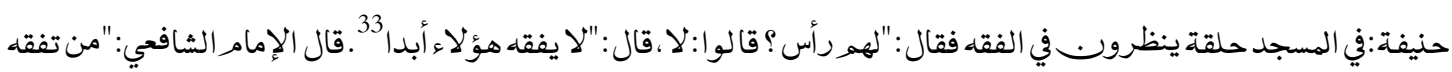
من بطوبـ الكتب ضيء الأحكام" "34قال ابن جابر: "لا يؤخذ العلم إلا ممن شهد له بالطلب"، قال أبو زرعة: فسمعت أبا مسهٍِ

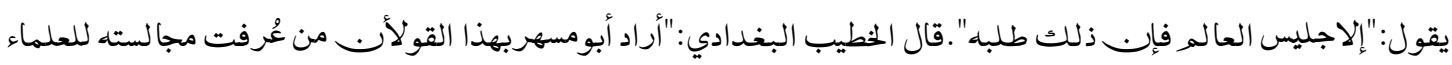
وأخذه عنهم. يكن في أخذ العلم. 35.عن صالح بن أحمد سمعت أب يقول ما الناس إلا من قال حدثنا وأخبرنا ولقد التفت المعتصمـ إلى

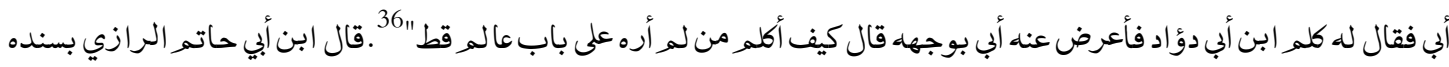

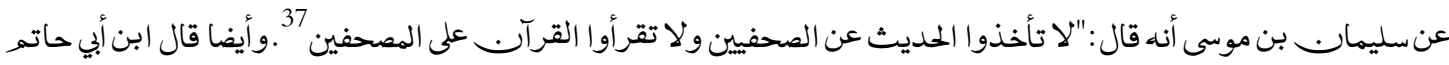

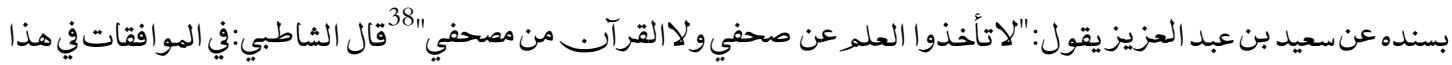

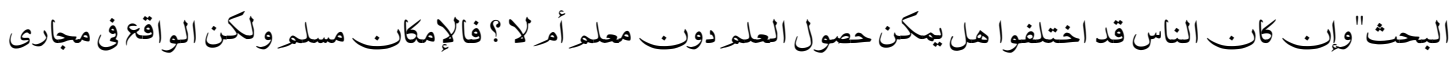




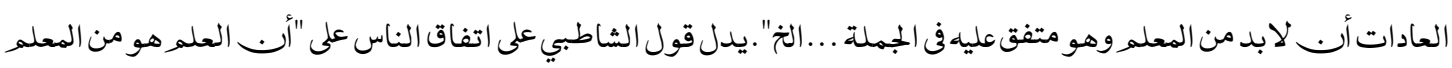
وعليه مجاري العادات وأما وقوء الإختلاف بين السواد الأعظه و بين الإمامية هو في صفات المعلم.ثم يقول الشاطبي:"وقد

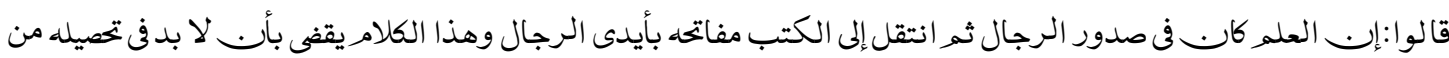
الرجال وأصل على هذا كما ورد في الصحيح "إِــ الله لا يقبض العلم انتزاعا ينتزعه من الناس ولكن يقبضه بقبض العلماء" .39. فإذا

كار كذلك فالرجال هم مفاتحه بلاشك فإذا تقرر هذا فلايؤخذ إلا ممنتحقق به وهذا الأنرو اضحو ومتفق عليه بين العقلاء .40. المطلب الثالث :الشيخ ناصر الدين الألباني وتلقيه العلمرمن الصحف: هل كالـ الشيخ الألباني من أهل الصحف أمرلا ؟ويكوبـ الجواب نعمـويؤيده هذه القرائن ـ أثناء دراسة الكتب التي ألفت في حياة الألباني وتحدثت أعماله الحديثية قدوضح لنا هذا الأمر:إلـ المؤلفين من مؤيديه قد اتفقوا على هذه النقاطووهي: 1

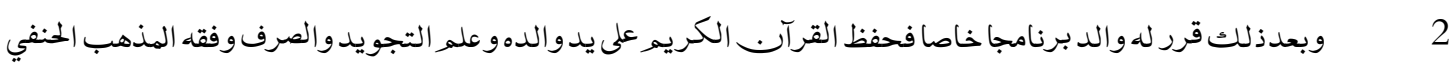
3 4 5 قد ذكرت في ترجمة الشيخ الألباني أسماء الكتب التي دَرّسها الشيخ الألباني ولكن ليس فيها ذكر كتاب واحد من متوبت الحديث أوعلوم الحديث،بل أنه يذهب إلى مكتبة الظاهرية يقرأ الكتب من الصباح إلى الليل حتى بعد مدة قليلة مؤظفو المكتبة وقف له غرفة خاصة للشيخ وهذا الدليل أنه أخذ المعلومات من قراءة الكتب الموجودةأفي المكتبة الظاهرية. 6 6 ليس له شيخا في الحديث ولم يرحل إلى بلاد أخرى لحصول الحديث كما جرى عليه عادة المحدثين منذ زمن الصحابة رضواسلـ الله أجمعين.

7 8 المطلب الرابع: تعريف المحدث وشرائطه وآدابه وهل توفرت شروط المحدث في الشيخ الألباني؟ كابـــالشيخ الألباني بعد التعلم من الدراسة الإبتدائية توجه إلى علم الحديث في نحو عشرين من عمره وكار. الشيخ الألباني مغرما في مطالعة و قراءة الكتب حيث يقول بنفسه "في أول عمري قرأت مايقرأ وما لا يقرأ".بدأ القراءة في"مكتبة الظاهريتة" بعدمتأثرا بمجلة الهناركمأققر بنفسهويقول:"فإذا كابـ من الحق أُبـ يعترف أهل الفضل بالفضل لذوي الفضل فإنني بفضل الله عزوجل بما أنا فيه من الإتجاه إلى السلفية أولا وإلى تمييز الأحاديث الضعيفة ثانيا يعود الفضل في ذلك إلى السيد محمد رشيدرضاعن طريق أعدادمجلة المنار التي وقفت عليهافي أول اشتغالي بطلب الحديث" ل4ه وبعد مدة قليلة أنه علق علي أحاديث كتاب الحافظ العراقي" المغني عن حمل الأسفارفي الأسفارفي تخريج مافي الإحياء من الأخبار".لكن الشيخ الألباني لم يجلس في

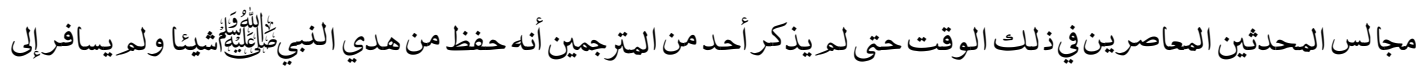


بلاد أخرى ولم يذكر في ترجمته أنه له رحلات علمية لحصول سند الحديث وعلومه وغيرذلك كما هي عادة المحدثين. الأول : تعريف المحدث وشروطه وآدابه "45 المحدث :هو من يشتغل بعلم الحديث رواية ودراية ويطلع على كثير من

الروايات و أحوال رواتحا46 الحافظ :هو مرادف المحدث عند كثير من المحدثين. 47

القول الثني:هوأعلى درجة من المحدث.كابـ الأئمة الكباريطلقوبـ هذه الكمة على من يشتغل بعلم الحديث

رواية ودراية وطلبا وسماعا وحفظا وجمعا وتصنيفا.قال أحمد بن العباس النسائى :"قال سألت أحمد بن حنبل عن رجل" يكوب. معه مائة ألفحديث ، يقال:أنه صاحب حديث؟؟ قال :لا.قلت:عنده مائتا ألفحديث، يقال :أنهصاحب الحديث؟ قال :لا. قلت

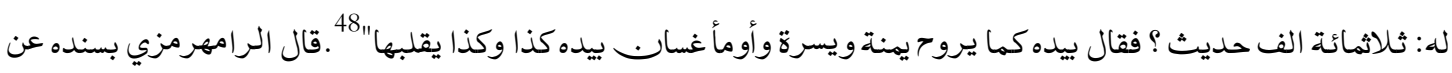

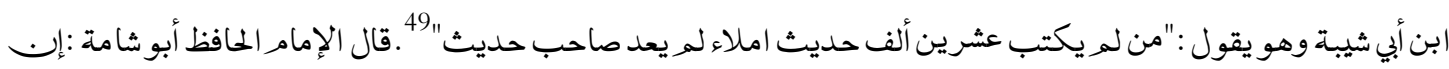
علوم الحديث الآّتـثثلاثة: الأول: "أشرفها حفظ متونه ومعرفة غريبهاووفقهها". الثاني: "حفظ أسانيدهومعرفة رجالها وتمييز صحيحها منسقيمها". الثالث: "جمعه وكتابته وسماعهو تطريقه وطلب العلوفيه"

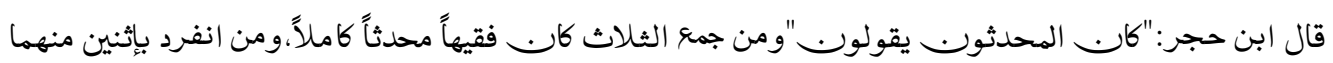
كار. دونه ، إلا أتـ من اقتصر على الثاني والثالث فهومحدث صرف، لاحظ له في اسه الفقيه ، كما أبـ من انفرد بالأول فلاحظ له في اسه المحدث".

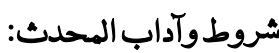

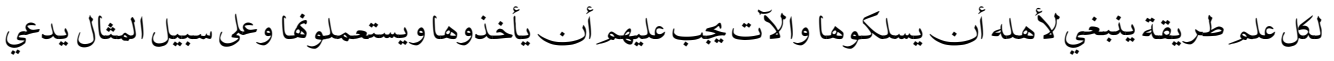
الرجل أنه من أهل الحديث وفي الحقيقة لم يحضر في مجا لس المحدثين مرة واحدة وكيف هو صادق في دعواه.قد بين الأصوليين في

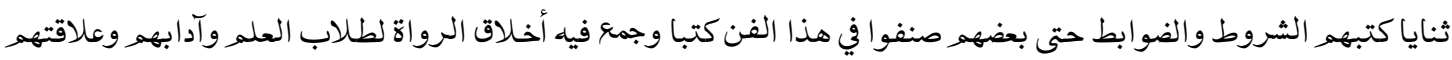
بشيوخهم وزملائهم وكل ما يتعلق بالدراية والرواية ومعرفة الرجال وغيرها. الإخلاص وتصحيح النية:يعني تصحيح النية وتطهيرقلبه من اغراض الدنيا. التحذيربلية حب الرياسة ورعوناتما قال ابن صلاح :"علم الحديث علم شريف يناسب مكارم الأخلاق ومحاسن الشيمـوينافر مساوي الأخلاق ومشاين الشيم 52 هذا من

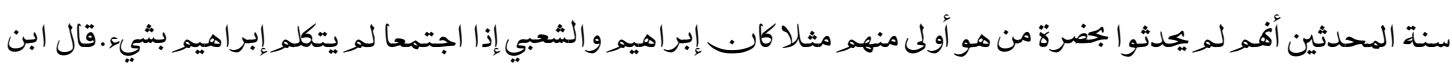
الصلاح:وقد اختلف في السن الذي إذا بلغ استحب له التصدي لإسماء الحديث والانتصاب لروايته والذي نقوله: إنه متى احتيج إلى ما عنده استحب له التصدي لروايته ونشرهفي أي سنكار. ينبخي للمحدث إذا التمس منه ما يعلمه عند غيره في بلده أو غيره بإسناد أعلى من إسناده أو أرجح من وجه آخر أبـ يعلم

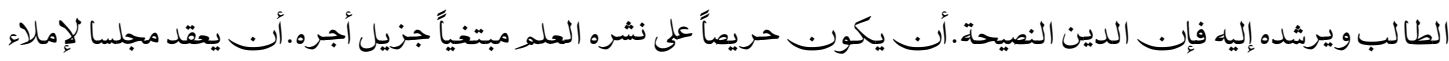




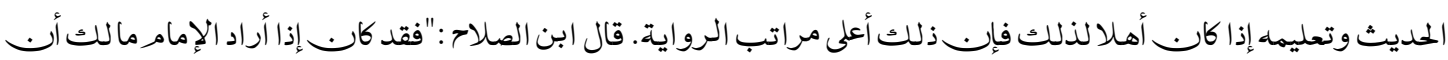
يجدث توضأ، وجلس على صدر فراشه وسرّ حلحيته وتمكّن في جلوسه بوقار وهيبة وحدث، فقيل له في ذلك؟فقال :"أحب أب.

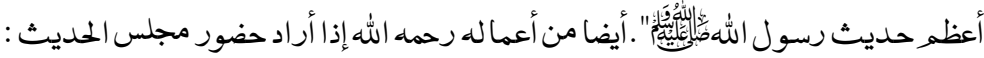

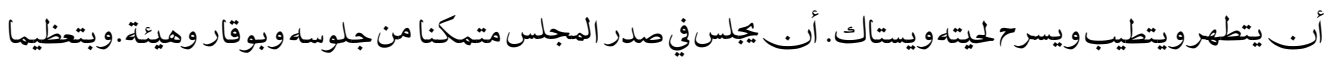

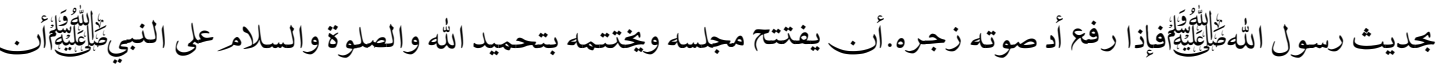
يجتنب ما لا تتحمله عقول الحاضرين أو ما لا يفهمونه من الحديث.أُ يُقِقبل على طلابه جميعاً ،لا يخص بعضهم بمزيد عناية دور بعض.

الثناء على الشيوخ:

يسسن بالمحدث الثناء على شيخه في حالة الرواية عنه بما هو أهل له، فقد فعل ذلك غير واحد من السلف الصالحين والعلماء.كما روى عن عطاء بن أبي رباح أنه كابــ إذا حدث عن ابن عباس رضي الله عنه قال: حدثني البحر.وعن وكيع أنه قال: حدثنا سفيال. أمير المؤمنين في الحديث، وأهم من ذلك الدعاء له عند ذكره فلايغفلن عنه 54

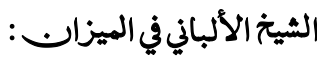
وظيفة المحدث هو الإشتغال بعلم الحديث رواية و دراية: المراد بعلم, الحديث رواية هو "أر. يشتغل المحدث

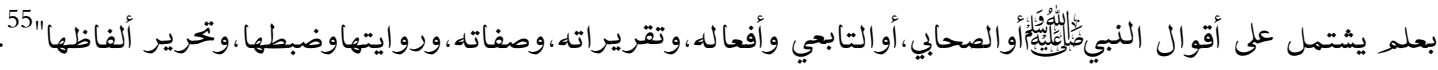
المراد علد الحديث دراية : "علم بقوانين يعرف بها أحوال السند والمتن" .أُ. في علمـ الحديث دراية يوصل إلى معرفة المقبول من المردود ،وبشكل عام أي بوضع قواعد حديثية ويطبق تلك القواعد على الحديث الذي يريد لمعرفة درجة الحديث من المقبول و المردود.لكن الشيخ الألباني لم يشتخل بعلم الحديث رواية وبدور. علم الرواية كيف يصل إلى علمر الدراية لأنه لمـيكفظ من

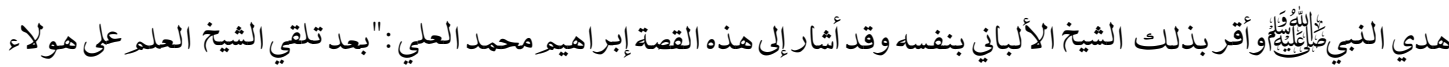
العلماء الفضلاء أكرمه الله بالتوجه لطلب بطلب علم الحديث الشريف رواية و دراية وعدم الإكتفاء بالقليل من ذلك العلم

$$
\text { ،وإنما سعى للتبحر فيه حتى أصبح مرجعا لطلبة العلمفي هذا العلمر الشريف" }
$$

وحدث الشيخ الألباني اقرارا عن نفسه "أبــنعمة الله علي كثيرة ولعل أهها نعمتين ـ النعمة الأولى :هجرة والدي وهو يسرلي تعله اللغة العربية وهذا ليس يمكن في الألبانيا. النعمة الثاني :تعليمه إياي مهنته اصلات الساعات.ثم بدأ الشيخ طلب علمر الحديثوهو في عشرين من عمره بتأثر مجلة الهنار المصرية ويعترف الشيخ الألباني بهذا يقول:"فإذا كابــ من الحق أُ. يعترف أهل الفضل بالفضل لذوي الفضل،فإنني بفضل الله عزوجل أولا ... الإتجاه إلى السلفية 57 .تمييز الأحاديث الضعيفة ثانيا. يعود الفضل في ذلك إلى السيد رشيد رضا عن طريق أعداد مجلة الهنار التي وقفت عليها في أول اشتغالي بطلب الحديث 58 .وأيضا يقول:ما أولحت بمطالعة من الكتب وهي القصصفي اللغة العربية كالظاهر وعنترة والملك سيف وما إليها ثم القصص البوليسية الهترجمة ثمـ وجدت نزوعاً إلى القراءات التاريخية.ثم اشتريت مجلة المنار ووجدت السيد رشيد رضا يصف فيه كتاب إحياء للإمام 
الغزالي.ثم أقبلت على قراءة الكتب وهذه الجهود شجعني أبــ أستعين بشتي المؤلفات اللغوية والبلاغية وغريب الحديث 59 لتفهمر النص إلى جانب تخرييه.

في أقوال الشيخ الألباني بعض المؤخذات منها. الأولى :لم يسلك أحد من السلف من المحدثين والمجتهدين حتي لم أجد مثال اواحدا من تاريخ الإسلامروهو أبــ الطالب يريد أبــ يأخذ علم الحديث رواية ودراية وهو بدأقرأة القصص والقرأة التاريخية 60.الثانية:هذا إقرار الشيخ قد وضح لنا أبـ الشيخ الألباني لم يتعلم علم الحديث،من أفواه الرجال بل أخذ علم

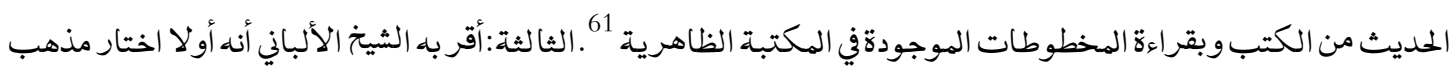
السلفية ثم يتوجه إلى تمييز الأحاديث الضعيفة ثم يتوجه إلى قراءة الكتب لمعرفة عله الأصول. اطلاء المحدث على كثرة الروايات:

من واجبات طالب الحديث أنه يطلع على كثرة روايات،وله رحلات علمية لطلب العله،ووعليه عمل منذ زمن

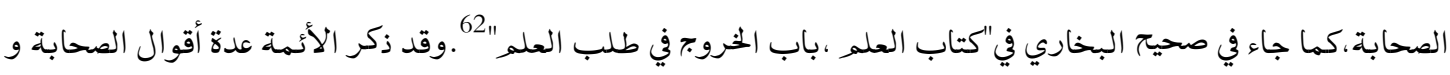
التابعين و من بعدهم في ثنايا كتبهر عن فضائل الرحلات لطلب الحديث الشريف وعلومه ومنهم الخطيب البغدادي ألف في هذا الموضوع كتابا مستقلاوسماه "الرحلة في طلب الحديث"ولم اذكر منها إلا إثنين منخشية التطويل : 1 ق 1 قال رسول الله صلى الله عليه وآله وسلمر:"من سلك طريقا يلتمس فيه علما سهّل الله له به طريقا إلى الجنة 63 2 وعليه عمل أهل العلم كما روي عن عمرو بن أبي سلمة يقول:قلت للأوزاعي:"أنا ألزمك منذ أربعة أيامـ ولم أسمع منك إلاثثلثين حديثا؟قل :وتستقل ثلاثين حديثا في أربعة أيامبكقد سار جابر بن عبد الله إلى مصر واشترى راحلة وركبها حتى سأل عقبة بن عامر عن حديث واحد وانصرف وأنت تستقل ثلاثين حديثا في أربعة أيام.؟.و أيضا من آداب رحلة لطلب الحديث هو أست يقدّم السماء من علماء بلده على الرحلة ولا يستخفنّ طالب العلم بأستاذه في بلده وجرى عليه عمل أهل الحديث.وأما

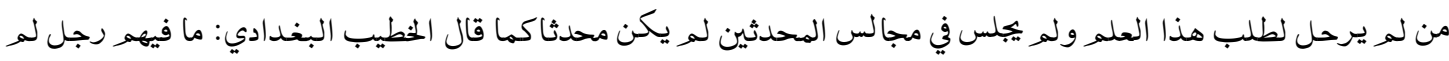
يرحل في طلب الحديث والعلم ولا يعتبر محدثا قط من لم يلق الشيوخ ويأخذ عنهم .65م يقول :"الرحلة إلى لقاء العلماء

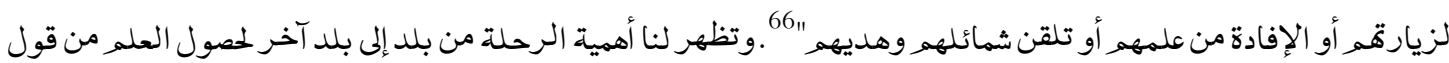

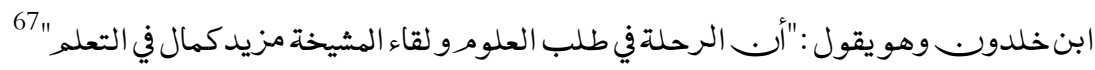
رحل المحدثين لأجل العلم لا لأجل الدنيا أو وظيفة ولا يطعموبـ وراء ذلك بل أما مهمر أهداف عظيمة وأهم منها هو "لأجل سماء الأحاديث والهصنفات" و"تخصيل الحديث ما ليس عنده "طلب العلو من الإسناد"البحث عن أحوال الرواة "والهذاكرة مع العلماء في نقد الأحاديث وعللها"، "ولإجازة الرواية من الشيوخ"-وإذبـــالرحال العلمية لها أهمية مسلمة لكل من يشتغل في حصول العلمرخاصة علمر الحديث رواية ودراية ولمر ينكر أحد عن أهميته. الرحلة في طلب الحديث و الشيخ الألباني: 
لمـ يذكر أحد في ترجمة الشيخ الألباني أنه رحل رحل لطلب علم الحديث وعلومه إلى بلد كذا وكذا بل هو لمـ يسمع من

شيوخ بلده كيف بدأ رحلته العلمية إلى بلاد أخرى،وهو مصداق قول الخطيب البغدادي وهو يقول:"رجل من لم يرحل في طلب الحديث لا يعتبر محدثا" فإِت. قيل :في هذا الزمن قد دونت كتب المتوبـ وعلوم الحديثلاحاجة لطلاب الحديث الرحلات العلمية ؟ .الجواب من أوجه :الوجه الأول:"إنما العلم بالتعلم "كما قال النبي عليه الصلوة والسلام.وقال الإمام الشاطبي على هذا الأمر اتفاق الناس على ذلك وجريار. العادة به كاف فى "إِـــ العلمـ كابــفى صدور الرجال ثمـ انتقل إلى الكتب مفاتحه بأيدى الرجال". الوجه الثاني :لو نظرنا في أحوال الأئمة لوجدنا أر. في عهدهم دونت كتب المتوبــوهذا الأمر معلوم أبــكتب

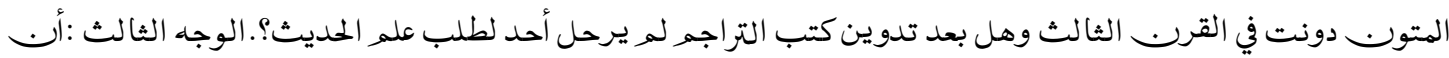

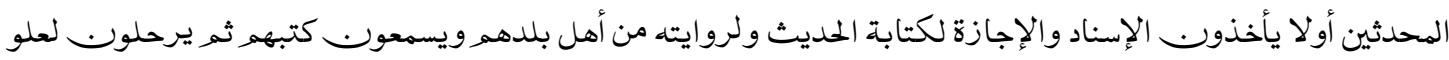
الإسناد ولمعرفة الأحكامروأصول الرواية والدراية كما تشهد كتب التراجم على جهودهم ورحلاتهم. ولنا برهابـ عظيم في قدوة الإمام أهل السنة وهو الإمامر محمد بن إدريس الشافعي رحمه الله خرج من مكة بعد دراسة إبتدئية إلى قبيلتة هذيل وكانت أفصح العرب وبتى فيهم سبعة عشر عاما رحل برحلتهم ونزل بنزولهمر ،ذه الرحلة لحصول كلامر العرب والأدب و الشعروقد مضي فيهـ سبعة عشر عاما.ثم حفظ الإمام الشافعي كتاب المؤطا وحفظه في تسع ليال ثمريخضر الإمام الشافعي في مجلس الإمام مالك ويقرآكتاب المؤطا وقام في المدينة إلى أبــتوفي رحمه الله تعالى وبعده رحل إلى العراق فلزم محمد بن الحسن الشيباني الحنفي وناظره على مذهب أهل المدينة. 69 وسبب هذه الرحلة هو فقط لحصول العلم وربما اختلف الإمام الشافعي في مسئلة عن رأي الإمام مالك لكن لم يطعن عليه ولمـ يعب قط.هذا الأدب قد جاء بسبب جلسة المحدثين وصحبة السلف الصالحين.و أيضاهذا هو الإمام البخاري رحمه الله بدأ طلب العلمر من عشر سنين أو أقل فلما بلغ في ست عشرة سنة، قد حفظ كتب ابن المبارك ووكيع ثم خرج مع أمه وأخيه إلى مكة، فلما حجه رجع أخوه بها!وتخلف هنافي طلب الحديث.ثََّّ رحل إلى المدينةوالشامـومصرونَيسابوروالجزيرة والبصرةوالكوفة، وبغداد وغيرهابلادأخري.هل اكتفى الإمام البخاري على حفظ كتب أهل بلده؟سيكوبـ الجواب لا، بل أنه لم يكتف على حفظ كتب ابن مبارك وكيع بل رحل بعده وحفظ

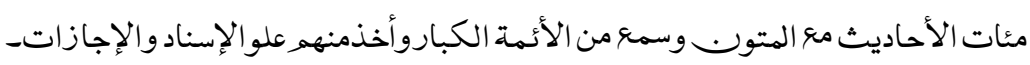

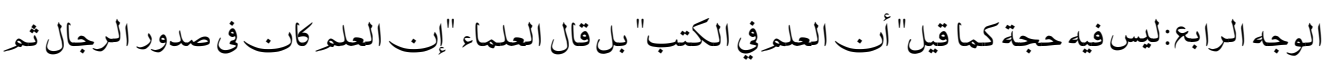
انتقل إلى الكتب مفاتحه بأيدى الرجال "كماقال الإمام الحافظ أبوشامة:إِــ علوم الحديث الآلـــثلاثة، الأول:أشرفها حفظ متونه ومعرفة غريبهاوفقهها.قلت(الباحث):وهذالشرط لم يتوفرفيه لأنه لم يحفظ شيئامن متوب الحديث. الثاني:"حفظ أسانيده ومعرفة رجالهاوتمييزصحيحها من سقيمها"قلت:وهذا الشرط أيضا مفقودا فيه ،لأنه لم يحفظ الأسانيد حتى لم يطلب لأحد سند الحديث وسند الكتب وكيف هو يطلب ؟ لأبــ ليس له شيخ في الحديث. الثالث: جمعه وكتابته وسماعه وتطريقه وطلب العلو فيه 70.قلت: لم يسمه من هدي النبي صلى الله عليه وآله وسلم كما هي عادة المحدثين ولم يرحل لطلب الحديث وبدورت الرحلات العلمية وسماء الحديث من الشيوخ كيف يمكن له أبـ يطلب علو الإسناد؟.ثم قال أبو شامة: "فيه ثلاثة 


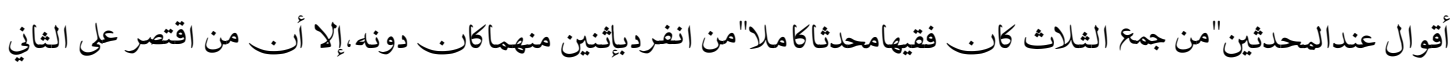

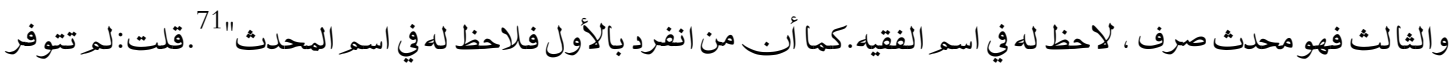
هذه الشروط الثلاثة في الشيخ الألباني وكيف يطلق عليه صفة المحدث أو الفقيه والله أعلم.

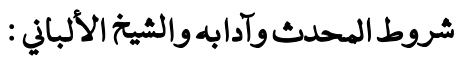

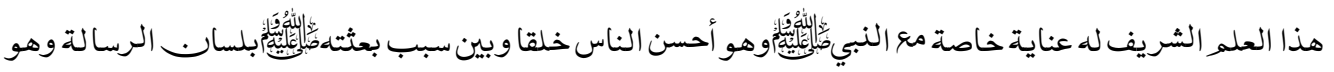

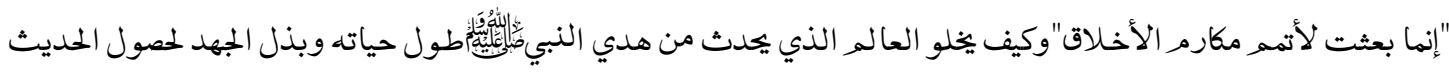
ورحل من بلد إلى بلد ولمر يحسن بجسن الأخلاق ولم يتعامل مع الطلاب بجسن معا ملته ويخالف في الرأي مع الأخرين لكن بجدود وقيودكمأجاز الإمام أعظم أبوحنيفة تللاميذه(قاضي أبو يوسف و الإمام محمد) أبـ يخالف في المسئلة معهويناقش هذا هو وسعة علمه، حتى نجد في كتب الفقه الحنفي في مسئلة واحد رأيين_الرأي الأول هوعند أبي حنيفة والثاني هو قول الصاحبين ـأماعن أماعن الشيخ الألباني عكس ذلك، إذا كابــ المحدث أو العالمـ اختلف معه في المسئلة أو الرأي أويرد عليه فيطعنه الشيخ الألباني طعنا شديدا ويعيبه حتى يشتمه ويلقبه بألفاظ أنه من أعداء السنة والتوحيد،كما قال في حق الشيخ محمود سعيد ممدو حصاحب الكتاب "تنبيه المسلمر"، يقول عنه:"هذا وأنا أكتب هذه المقدمة وفوجئت بهاقد جديد وباغ بغيض ألا هو المدعو محمود سعيد بن ممدوح "73.ثم يقول:"ولكنه مع الأسف الشديد سلك فيه سبيل من قبله من الحاقدين و الحاسدين الذين يخالفوب. سبيل المؤمنين في الرد على المخالفين بزعمهم ولا غرابة ذلك فإنه من تلامذة محمد عوانة الحلبي وبلديه أبوغدة وهذامن أصدقاء الأنصاري وكذلك من شيوخه بعض الغماريين المشهورين بجقدهم وأعدائهمر الشديد لأهل السنة والتوحيد".ثم يسب سبا شديدا على الشيخ الأنصاري الباحث في دار الإفتاء بالمملكة العريية السعودية،حين ألف كتابا في رده وسماه"تصحيح حديث صلاة التراويح عشرين ركعة والرد على الألباني في تضعيفه"ومعه"إباحة التخلي بالذهب المحلق للنساء والردعلى الألباني في تحريمه"بسبب التباء هذاالكتاب صار الشيخ غضباب. عليه وطعنه وسببه سباشديدا وقال عنه:"فلينظر القاري الكريم إلى خباثة هذا الرجل الذي يكاد قلبه يقطر دما حسدا وحقدا إنه يسئل ما كرا ويجيب من عنده من نفسه باغيا .... الخ "74. أيضا ثم يقول "وإِ. من تلاعب هذا الرجل الدال على أنه يلعب على الحبلين ولنا أمثلة كثيرة مثل هذه الطعن والتشنيع على أهل العلم ومقدمات كتب الشيخ الألباني مملوءة مثل هذه السب والشتمـ والطعن,مثلا:قال الشيخ الألباني مثنياعلي المحدث حبيب الرحمن الأعظمي في مقدمة"صحيح الترغيب و الترهيب": "واعلد أس. مماشجعني على نشرهما.... العالمـ الشهير الجليل الشيخ حبيب الرحمن الأعظمي" وفي نفس الصفحة يقول "ومما زادني رغبة في الإقبال عليه ، أس محققه الفاضل الشيخ حبيب الرحمن الأعظمي 76.وحين وقع الإختلاف مع الأعظمي قال في مقدمته الجديدة ل"آداب الزفاف"عنه:"واستعابـ الأنصاري بآخر رسالته بأحد أعداء السنة وأهل الحديث ودعاة التوحيد المشهورين بذلك ألا وهو الشيخ حبيب الرحمن الأعظمي لجنبه وفقدانه الشجاعة العلمية والأدبية.ثم يقول الشيخ الألباني "واستعانته في آخرها بأحد أعداء السنة وأهل الحديث ودعاة التوحيد المشهورين بذلك ألا وهو الشيخ حبيب الرحمن الأعظمي" 
ايضا:" وأما الأعظمي فله في هذا المجال تشكيكات بل تضليلات أخرى 78.كل من ينبهه على أخطاءه من أهل العلمـ ولم يذهب ما ذهب إليه الشيخ الألباني فهو يرميه بعبارة"عدو السنة و التوحيد" أو "عدو أهل السنة و التوحيد"وغيرذلك.هذا ليس من أخلاق المحدثين والعلماء لألــ أول الشرط للمحدث هو أبــ يتصف مكارم الأخلاق وأيضا هذا شرط أساسي لقبول رواية المحدث أر. يتصف بالعدالة والعدالة تثبت فيه أبــ يكوبـ سليما من أسباب الفسق وسليما من خوارم المروءة.

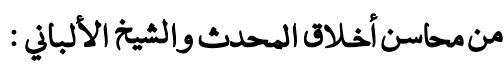

تقدم قليلا محاسن أخلاق المحدث ولم أكرره ولكن هذه المحاسن فقدت من أخلاق الشيخ الألباني وله أسباب منها: السبب الأول: لم يحضرفي مجلس المحدثين لأنه أخذعلم الحديث الشريف من الكتب كماتقدم. السبب الثاني:لمريكفظ الشيخ من

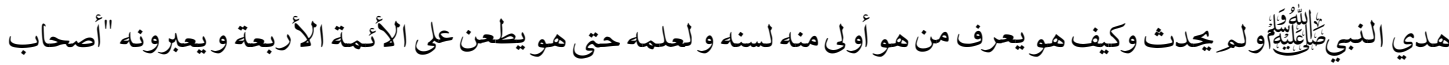
مذاهب الضالة"سواء في الفقه أمرفي العقيدة أي من الأشاعرة و الماتريدية، كماتنظر في مقدمات كتبه. السبب الثالث:أس يُقبل على طلابه جميعاً. لم يقرأ الشيخ الألباني الحديث على طلابالحديث كعادة المحدثين. السبب الرابع: الثناء على الشيو خ:يكسن بالمحدث الثناء على شيخه في حالة الرواية عنه بماهوأهل له، فقد فعل ذلك غير واحد من السلف الصالحين والعلماء ، لكن الأمر عكس ذلك عند الشيخ الألباني.كما ذكرت في أقوال معاصري الشيخ الألباني أنه يطعنويعيب كثير على الأئمة الكبار من الفقهاء والمحدثين و الأصوليين وتطاول على الأئمة الأصوليين مثلا الإمامر الحاكم والحافظ الذهبي وابن الجوزي والحافظ ابن حجر العسقلاني و الشيخ المناوي والشيخ أبو الفتاح أبوغدة الشيخ السيد الغماري وغيرهم.وأهم سببه هذا الشيى هو أبـ الشيخ الألباني لمـ يذهب لتحصيل العلمفي مجا لس أهل العلمـو لا يأتي الأدب وحسن الخلق إلا من الشيوخ .وهذا الأمر يشير إلى أب. الشيخ الألباني لمريتصف بأوصاف المحدثين.

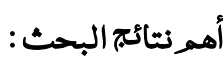

توجه الشيخ الألباني إلى علمر الحديث متأثرا مجلة المنار. بعد متأثرا بمجلة الهنار لمر يتوجه إلى علماء الأمصار من المحدثين والأصوليين من عصره بل يتوجه إلى مكتبة الظاهرية وبدأقرأءة الكتب ومضى الوقت في قراءةالكتب من الصباح إلى المساء. يتعلم علم الحديث من قراءة الكتب في المكتبـة الظاهرية. وإذبـــهو من أهل المصحفي. كابـ الشيخ الألباني بذل جهدا كبير افي تخريج الحديث وعلق على كتب كثيرة. قال الشيخ أحمد بنييي النجمي:"الشيخ محمد ناصر الدين الألباني المحدث الكبير...الخ". قلت :في الواقع أُ الشيخ الألباني لم يحفظ شيئا من هدي النبي صلى الله عليه وآله وسلمسندا ومتنا. كابــــالشيخ الألباني تعلم العلمر من قراءة الكتب في المكتبة الظاهرية وصار إما ما مجتهدا ومحدثا كما صر جلميذه الشيخ عاصم عبد الله القريوتي رسالته"ترجمة موجزة لفضيلة المحدث"والشيخ إبراهيم محمد على في تأليفه"علماءو مفكرور. معاصروب لمحات من حياتهم وتعريف مؤلفاتمـر". 
لم يرحل الشيخ الألباني الرحلة العلمية لطلب الحديث،وإذلـ نسبة "إصطلاح المحدث إليه"فيه نظر وكما قال الخطيب البغدادي:"رجل من لمريرحل في طلب الحديث لا يعتبر محدثا". كابـ الشيخ الألباني يطعنويعيب كثير اعلى كل من ذهب بخلاف مذهبه أو يرد عليه. لم يتوفر في الشيخ الألباني شروط المحدث مثلا حفظ السنة النبوية متنا وسندا والرحلات العلمية لطلب علم الحديث وأصوله وإجازة الرواية من الشيوخ،ورحسن الإخلاق.

قال الخطيب البغدادي "من لمـ يأخذ الحديث من أفواه العلماء لا يسمى محدثًا بل يسمى صحفيا ،ولا شك فيه أبـ الشيخ الألباني لمريتعلمر من الشيوخ في مجال عله الحديث شيئا.

\section{المصادروالمراجع}

$$
\text { 164:3 آل عمراب }
$$

ذذكر الإمام البخاري في صحيحه معلقا ، كتاب العلم ،باب العلم قبل القول والعمل،ص 37 3 البخاري، الإمام محمد بن إسماعيل البخاري ، الجامع الصحيح ،كتاب العلم، باب الحرو.ج في طلب العلم، دار السلام للطباعة والنشر والتوزيع،

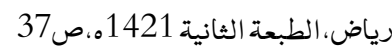
ا القشيري، الإمام مسلم بن الحجاج النيسابوري ،مقدمة صحيح مسلم ، بيالـ أبـ الإسناد من الدين ،دار السلام للطباعة والنشر والتوزيع ،

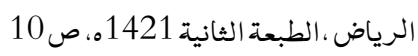
5 الألباني نسبة إلى ألبانية والبانية بلد اسلامي يقع في جنوب شرق أوربا يجده من الجنوب الشرقي اليونابــومن الشمال يوغسلافيا. 6 العاصمة العثمانية تعرف اليوم بإستنبول

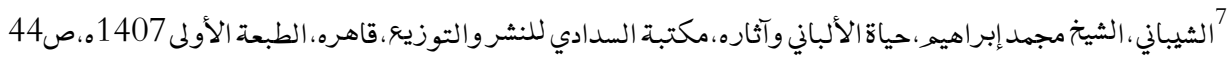

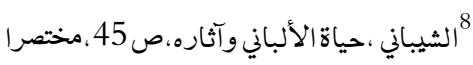

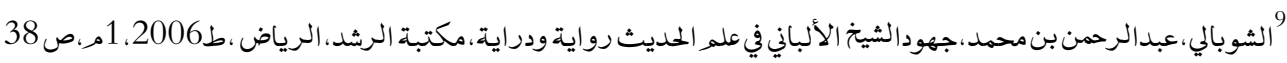

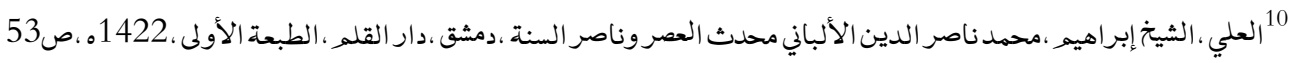

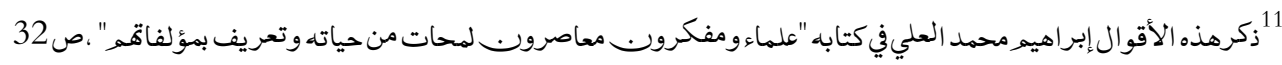
12 كوكبة من ائمة الهدي، صرمد الاقواليراهير 252 131الطنطاوي، الشيخ علي الطنطاوي ، الفتاوى جمعها ورتبها حفيده مجاهد ديرانية ،دار الهنارة للنشر والتوزيء، السعودية الطبعة الأولى 1405ه. الهوافق 1985م، جدة، ص 157_انظر فتاوى الشيخ على الطنطاوي ،ص 159158

15 السيد أبو الفضل عبد الله بن محمد بن الصديق الغماري الحسني الإدريسي. ولد سنة 1328ه وهو من علما الأزهر. انظر:كيف تكوب. محدثا الرواية مع الدرايةص 103، 10 مختصرا

16 الغهماري ، الشيخ عبد الله بن الصديق ، القول المقنغ في الرد على الألباني المبتدع ، ص 6.

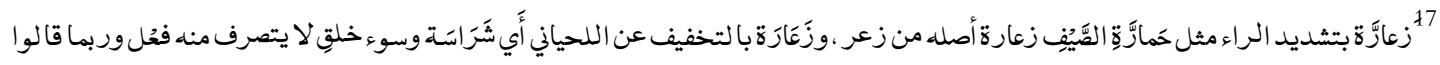




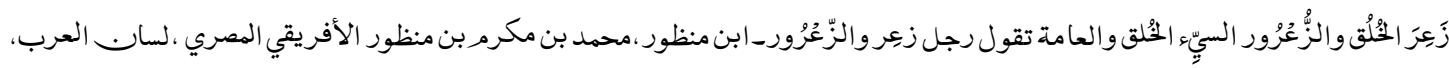

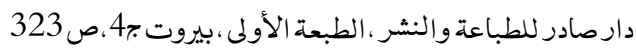

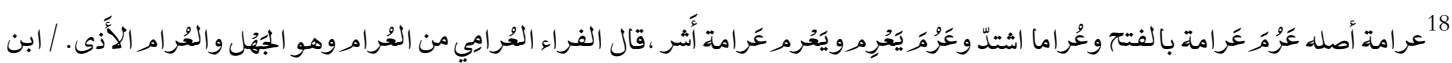

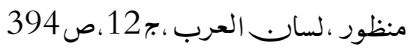

19 أيضا ، ومن يريد التفصيل في هذا الموضوع فليرجع إلى كتاب "قاموس شتائم الألباني" للسقاف صلف

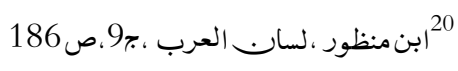

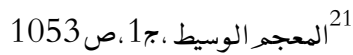

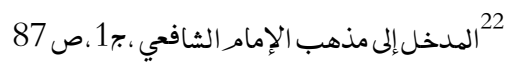

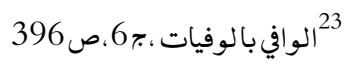

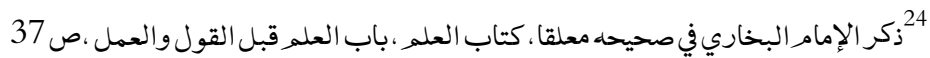

25 الترمذي ، الإمام أبو عيسى محمد بن عيسى، جامع الترمذي، كتاب العلم، دار السلام للطباعة والنشر، الرياض،

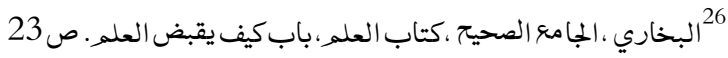

27

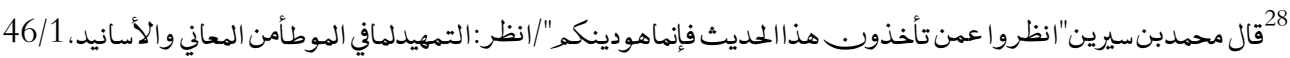

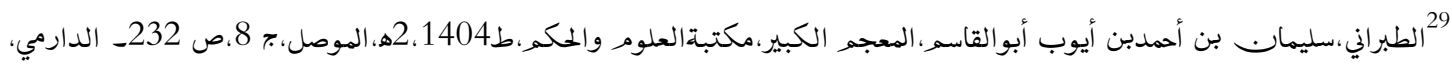

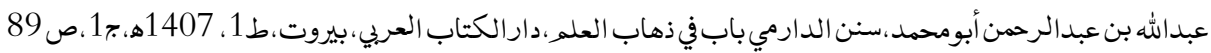

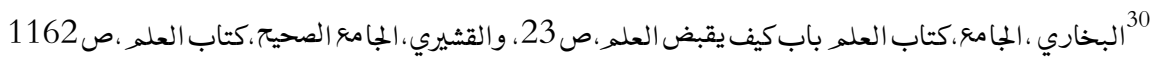
31 ذكره الإمام البخاري في صحيحه معلقا،ص 37_قال الإمام العيني "أخرجه ابن أبي عاصه بهذا اللفظ (يفقه )في كتاب العلم من طريق ابن عمر

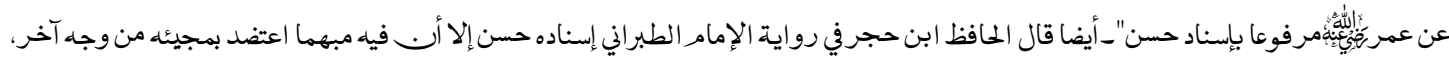

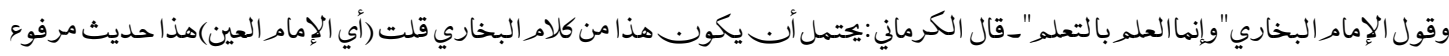
وبعد ذلك بين تخريج هذا الحديث المعلق_تخريج هذا الحديث :أخرجه الإمام الطبراني في مسند الشاميين ، ج1،ص ص 431 من مسند عتبة بن أبي حكيم الهمداني بإلفاظ مختلفة وهنا ذكر الإمام الطبراني في مسند الشاميين" ،"ولن تزال أمتي على الحقى ظاهرين... الخ"اما في المعجم الكبير اخرجه

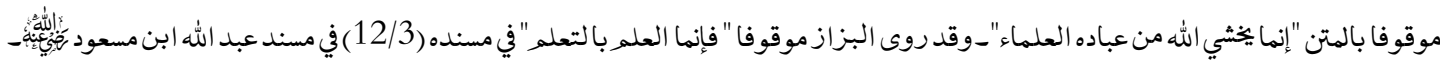
32 هو محمد بن إبراهيه بن سعد الله بن جماعة الكناني الشافعي لقبه بدر الدين أبل بدر الدين ابن جماعة ولد بجمالة سنة 639 هـ/انظر طبقات

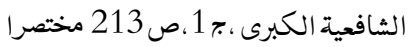

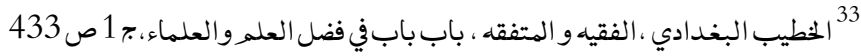

$$
\begin{aligned}
& \text { 34 النووي، المجموع شر ح المهذب، ب1، ص38 } \\
& \text { 35 } 35 \text { الخطيب البغدادي، الكفاية في علم الرواية ، ج2، ص288 } 288
\end{aligned}
$$

36 القاضي عياض المالكي ، الإلماء إلى معرفة أصول الرواية وتقييد السماع،دار التراث، الهكتبة العتيقة القاهرة 1379هـ، جـ 1، ص28 28

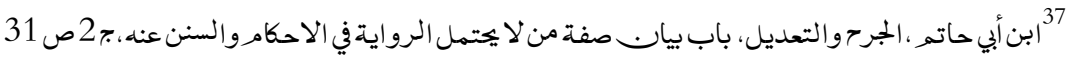




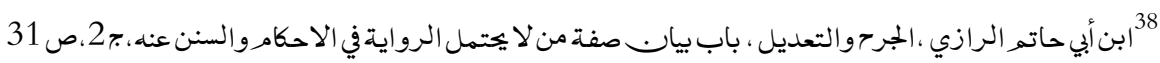

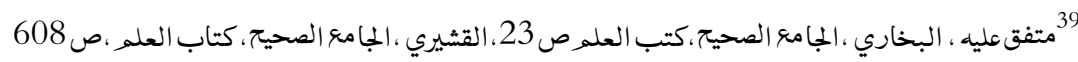
40 الشاطبي، إبراهيمربن موسى اللخمي الغرناطي المالكي، الموافقات في أصول الفقه،دارالمعرفة للطباعة والنشر بيروت جـ 1، صو 92

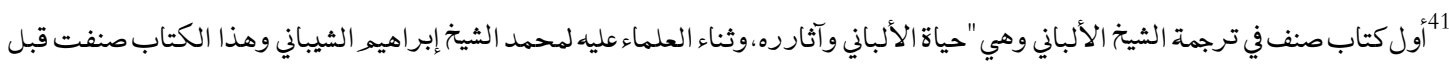
وفاة الهترجم تقريبا 13سنة و قرئ على الهترجم وعلق الشيخ الألباني وسئل الشيخ الألباني عن هذه الكتاب" هل عندكم زيادة عما كتبه الشيخ

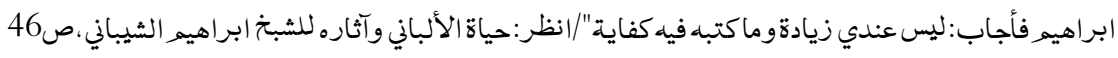

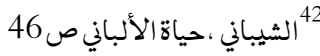

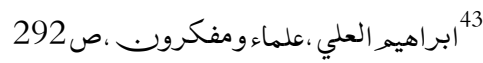

$$
\begin{aligned}
& \text { 44 الشيباني ،حياة الألباني ،ص } 401
\end{aligned}
$$

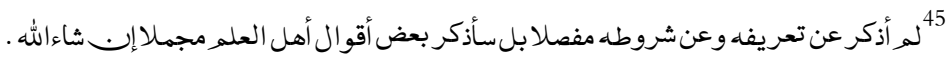

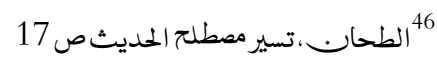

47 كتب عامة في مصطلح الحديث وعلومهـقال الإمام السيوطي :كالـــالسلف يطلقوب. المحدث والحافظ في معنى واحد كما روى أبوسعد السمعاني بسنده إلى أبي زرعة الرازي:سمعت أبا بكر بن أبي شيبة يقول:من له يكتب عشرين ألف حديث إملاء لم يعد صاحب حديث.قال ابن عدي:من

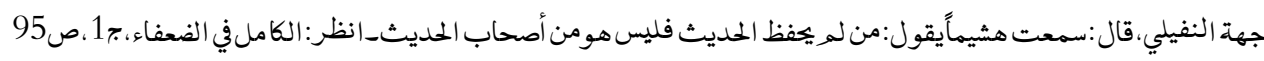

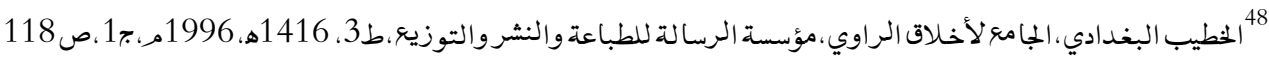

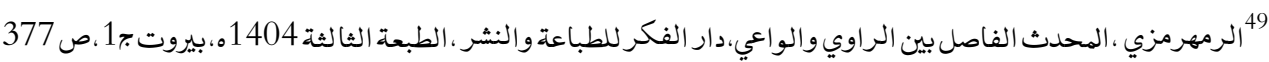

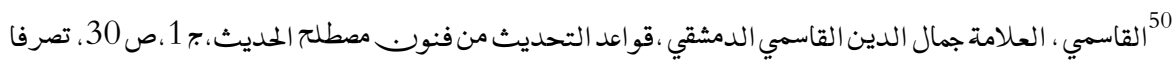
51

52 ابن الصلام، أبوعمروعثمار بن بن عبدالرحمن الشهرزوري، علوم الحديث ،مكتبة الفارابي،ط1، 1984م،ص 137، مختصرا 53 54 55 55

56 براهير محمد العلي، محمد ناصر الدين الألباني محدث العصر ، وناصر السنة ،ص صلم 13 57 57 الشيخ عبد الله بن محمد الشمراني صاحب الكتاب"ثبت مؤلفات المحدث الكبير للإسلام محمدناصر الدين الألباني ص 16

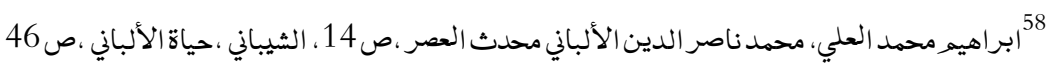

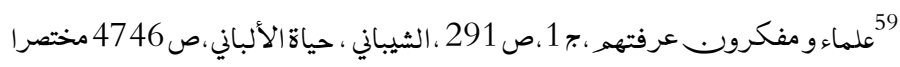
60 مثلا الإمام البخاري رحمه الله بدأ طلب العلم من عشر سنين أو أقل كما يقول:"فلما طعنت في ست عشرة سنة، كنت قد حفظت كتب ابن الهبارك ووكيع ثم خرجت مع أمي وأخي أحمد إلى مكة، فلما حججت رجع أخي بها ! وتخلفت في طلب الحديث.ومن رحلاته العلمية كالـ هذا

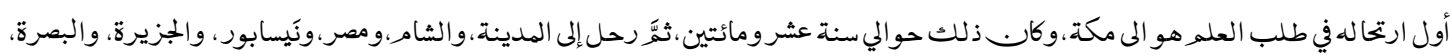
والكوفة، وبغداد، وواسط، ومرو، والرّيّ، وبَلْخ، وغيرها . وهذا مبلغ علم الإمام البخاري رضي الله عنه. 


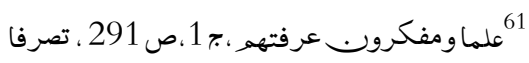

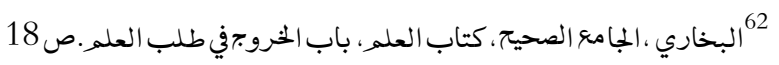
63 ابن حنبل، الإمام أحمد بن حنبل، مسند الإمام أحمد بن حنبل جـ2، ص 352 ، 35 ، في مسند أبي هريرة رضي الله عنها

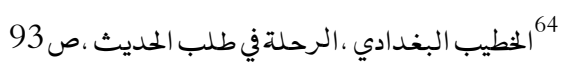

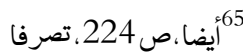
66 أيضا 67 68

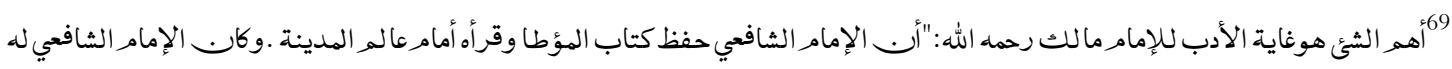
كلام كثير في الإمام مالك بن أنس كما ذكره أهل العلم مثلا من أقوال الإمام الشافعي في حق الإماه مالكت رحمه الهه. قال الشافعي رحمه الله:مالك

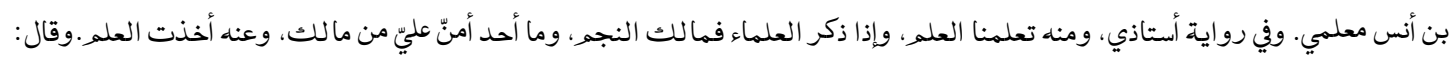

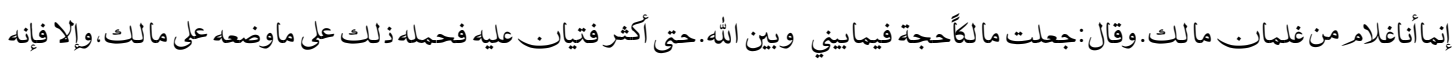
كابـ الدهر كله إذا سئل عن الشيء قال:هذا قول الأستاذ"من أين جاء هذا الأدب للشيخ و أداب الفتوي وأداب إختلاف الرأي مع الآخرين هويأتي

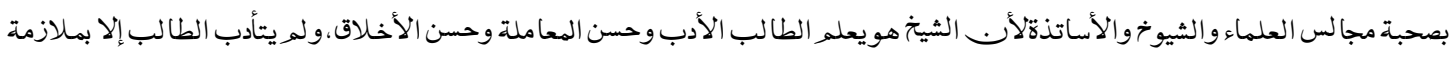

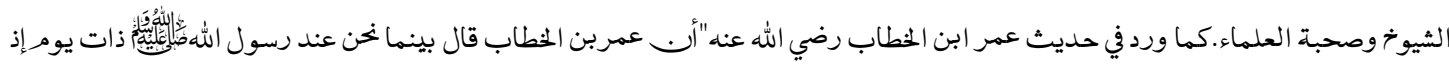

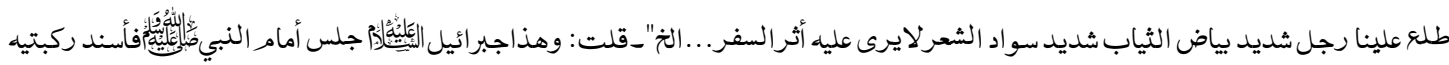

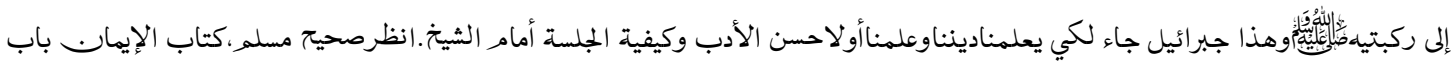

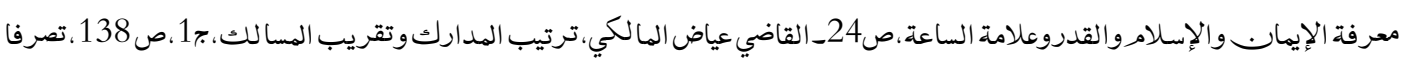

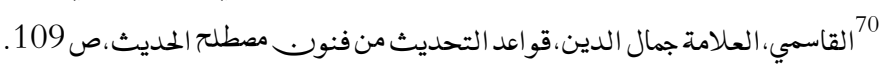
71 72 الصاحبين وهذا إصطلاح فقهي يستعمل في الفقه الحنفي يرادبه أبويوسف يعقوب بن إبراهيم قاضي القضاتوالإمام محمدبن الحسن الشيباني وهما من أشهرتلامذة الإمام أبي حنيفة رضي الله عنهم.

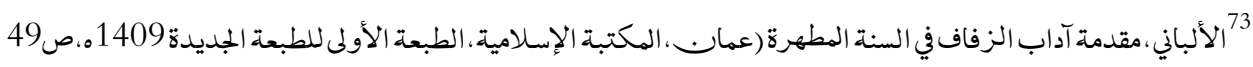

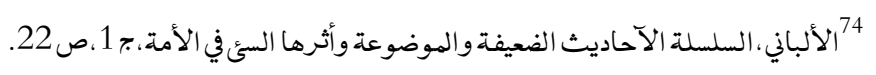

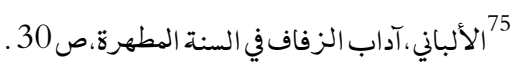
76 الألباني، صحيح الترغيب والترهيب، الباف 63

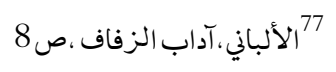

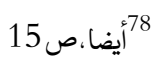

\section{(2) $(0)$}

This work is licensed under a Creative Commons Attribution 4.0 International License. 